\title{
Fatty Acid Profile and Total Lipid Content of Chionoecetes opilio Shells
}

\author{
María Vilasoa Martínez, Ana Rodríguez-Bernaldo de Quirós*, Julia López Hernández and \\ M. Asución Lage Yusty
}

\author{
Department of Analytical Chemistry, Nutrition and Bromatology, Faculty of Pharmacy, University of Santiago de \\ Compostela, 15782 Santiago de Compostela, Spain
}

\begin{abstract}
In the present study, the Soxhlet method was used to determine the total lipid content of Chionoecetes opilio shells. Several parameters were optimized in order to achieve the maximum extraction efficiency.

The fatty acid profile was determined by gas chromatography-flame ionization detection using a one-step-extractionmethylation method to obtain fatty acid methyl esters. GC-MS was used as a confirmatory technique.

Twenty-one fatty acids were identified, and as it was expected, a high content of $\omega-3$ polyunsaturated fatty acids were found, representing $36 \%$ of the total fatty acid content.

The results obtained indicate that snow crab shells might be considered as an innovative source of $\omega 3$ long chain polyunsaturated fatty acids for aquaculture feeding purposes.
\end{abstract}

Keywords: Lipids, Soxhlet, Fatty acids, GC-MS, Chionoecetes opilio.

\section{INTRODUCTION}

The Snow crab, Chionoecetes opilio (Brachyura: Majidae), is an important commercial species in the northwest Atlantic. Crabs, among many others invertebrates, are considered to be important shell fishery products [1], and are widely used as food and feed supplements throughout the world. The demand for products derived from fishing has increased considerably; this has prompted a sustained upward development in aquaculture activity in the last decades. Fatty acids, such as eicosapentanoic acid (EPA), docosahexanoic acid (DHA) and arachidonic acid, are considered essential for marine fish and must be provided in the diet. Marine species are one of the main sources of polyunsaturated fatty acids [2-9].

Several procedures for total lipid extraction (Soxhlet, Bligh \& Dyer, Rosse-Gottlieb, etc.) have been described in the literature [10-12]; however there is no unanimous opinion on the most convenient technique. Most of the commonly used techniques are time-consuming, laborious, and large volumes of toxic solvents are required. More recently, supercritical fluid extraction (SFE) has been reported in the bibliography as an excellent alternative to the conventional techniques $[13,14]$.

The study of total fat content as well as the fatty acid composition, especially polyunsaturated fatty acids (PUFAs) and $\omega-3$ in seafood products is of great interest due to their beneficial effects on coronary diseases $[7,9,15]$. The technique most commonly used for fatty acids analysis is the gas chromatography coupled with a flame ionization detector (GC-FID).

*Address correspondence to this author at the Department of Analytical Chemistry, Nutrition and Bromatology, Faculty of Pharmacy, University of Santiago de Compostela, 15782 Santiago de Compostela, Spain; Tel: +34 981 598450; Fax: +34 981 594912; E-mail: ana.rodriguez.bernaldo@usc.es
The major aim of this study was to demonstrate the nutritional value of $C$. Opilio shells for use as feed in fish farms. As a results, the total lipid content and the fatty acid composition of Chionocetes Opilio shells were investigated.

\section{MATERIALS AND METHODOLOGY}

\subsection{Samples}

Crabs (Chinoecetes Opilio) were collected from the North Atlantic coastal region between Greenland and Canada in November 2005. The edible parts were removed manually. The shells were frozen in the ship and transferred to our laboratory. After defrosting, the shells were dried in a vacuum oven at $50^{\circ} \mathrm{C}$ until constant weight was reached. Finally, the samples were powdered and stored in the dark.

\subsection{Chemicals}

Fatty acid methyl ester mix (PUFA No 3); cis-11, 14eicosadienoic acid methyl ester; cis-8, 11, 14-eicosatrienoic acid methyl ester and cis-11, 14, 17-eicosatrienoic acid methyl ester were obtained from Supelco (Bellefonte, PA, USA). Methanol, petroleum benzine, $\mathrm{HCl}, \mathrm{CO}_{3} \mathrm{~K}_{2}$, and $\mathrm{SO}_{4} \mathrm{Na}_{2}$ were purchased from Merck (Darmstadt, Germany). Toluene was obtained from Sigma-Aldrich (EEUU). All other reagents were of analytical grade. Ultrapure water was obtained from a Milli-Q water purification system Millipore (Bedford, MA, USA).

\subsection{Lipid Extraction}

Total fat was extracted according the standard AOAC method [16]. One g of dry and homogenized samples, $10 \mathrm{~g}$ sea sand, and $200 \mathrm{ml}$ petroleum benzine were extracted by Soxhlet for 7 hours. Then, the solvent was evaporated at 35 ${ }^{\circ} \mathrm{C}$ using a rotary evaporator. Finally, the lipid content of samples was determined gravimetrically. 


\subsection{Fatty Acid Analysis by GC-FID}

The samples were processed using an extraction procedure which involves extraction-methylation in a single step [17]. About $0.4 \mathrm{~g}$ of each sample was weighed in a $160 \times 16$ $\mathrm{mm}$ Pyrex tube fitted with a PTFE-lined screw cap. Then, 2 $\mathrm{mL}$ of toluene and $3 \mathrm{~mL}$ of freshly prepared $5 \%$ methanolic $\mathrm{HCl}$ were added. After carefully mixing the contents and flushing the headspace of the vial with nitrogen, the tubes were heated for $2 \mathrm{~h}$ in a water bath at $70{ }^{\circ} \mathrm{C} . \mathrm{K}_{2} \mathrm{CO}_{3}(6 \%)$ solution $(5 \mathrm{~mL})$, toluene $(1 \mathrm{~mL})$ and $1 \mathrm{~mL}$ of nonadenoic acid methyl ester (I.S. toluene solution) were added after cooling the tubes.

The tubes were vortex-mixed and immediately centrifuged at $139.5 \mathrm{~g}$ for $5 \mathrm{~min}$ in a Hettich EBA 12 centrifuge to separate the phases. The organic layer was dried with anhydrous $\mathrm{Na}_{2} \mathrm{SO}_{4}$ and $1 \mu \mathrm{L}$ of liquid phase was injected into the chromatograph.

The fatty acid methyl esters analysis was performed with a Fisons GC-8000 (Manchester, UK) fitted with a splitsplitless injector and a Fisons EL-980 flame ionization detector (FID) equipped with a DW-Wax capillary column (60 m X $0.32 \mathrm{~mm}$ i.d. fused-silica column coated with a $0.25 \mu \mathrm{m}$ polyethylene glycol film) (J\&W Scientific, Folson, CA, USA). Peak areas were processed using Chrom-Card for Windows (Carlo Erba) software (version 1.18). Samples (1 $\mu \mathrm{L})$ were injected with a split ratio of 1:15 at a column temperature of $160{ }^{\circ} \mathrm{C}$ and an injector temperature of $250{ }^{\circ} \mathrm{C}$. The carrier gas used was helium at a flow-rate of 1.35 $\mathrm{ml} / \mathrm{min}$, an average linear velocity of $22.76 \mathrm{~cm} / \mathrm{sg}$ and a head pressure of 15 p.s.i. One minute after injection, the temperature was raised at $3.5^{\circ} \mathrm{C} / \mathrm{min}$ to $230^{\circ} \mathrm{C}$ and held for $20 \mathrm{~min}$. The detector temperature was $260{ }^{\circ} \mathrm{C}$. The fatty acid methyl esters profile of all samples were identified by comparison of their retention times with standards.

\subsection{Fatty Acid Analysis by GC-MS}

For mass spectra analysis, a Fisons MD 800 (Manchester, UK) mass detector and Masslab software (version 1.4) were used. The mass spectrometer operated under the following conditions: ion ionization voltage, $70 \mathrm{eV}$, mass range, 50-
$450 \mathrm{~m} / \mathrm{z}$ and scan and inter-scan delay times of $0.45 \mathrm{sg}$ and $0.05 \mathrm{sg}$, respectively. The oven programme temperature was the same as the methodology described under the GC-FID analysis.

The compounds were identified by comparison of their mass spectra with the Wiley (New York, USA) mass spectrum library (version 1.4).

\section{RESULTS AND DISCUSSION}

\subsection{Total Lipid}

Since the selection of the organic phase is a critical step in the Soxhlet extraction different organic solvents were tested; hexane, dichloromethane and petroleum benzine. The best results were achieved when using petroleum benzine. The yield of total lipids obtained in samples tested was around $12 \%$ higher than the yields obtained with the other solvents. In addition, the evaporation of the solvent was shorter because of the lower boiling point of petroleum benzine. Soxhlet extraction is a convenient automated method for lipid extraction from solid samples $[10,18]$. Katikou and Robb [18] also used petroleum benzine to extract the fat from salmon samples. In this study, the authors compared the CEM rapid extraction method with the soxhelt for the determination of lipid content in fillets of farmed Atlantic salmon. The lipid values obtained with the soxhelt method were higher than those obtained with the CEM method, although the differences were not significant.

The total lipid yield obtained for 40 samples, expressed as $\mathrm{g} / 100 \mathrm{~g}$ of dry weight, was $(21.9 \pm 8.4)$ (mean $\pm \mathrm{SD})$. In the Fig. (1), the percentage of fat obtained of each sample analysed is presented. As can be seen, the fat content in the samples varied from $2.53 \%$ (sample 6) to $37.86 \%$ (sample 33).

\subsection{Fatty Acids}

In the second part of the work, the fatty acid methyl esters (FAMEs) profile was determined. Although there are several studies on the fatty acid composition of different species of crabs [19-21], no information about the content of fatty acids of snow crab shell is available.

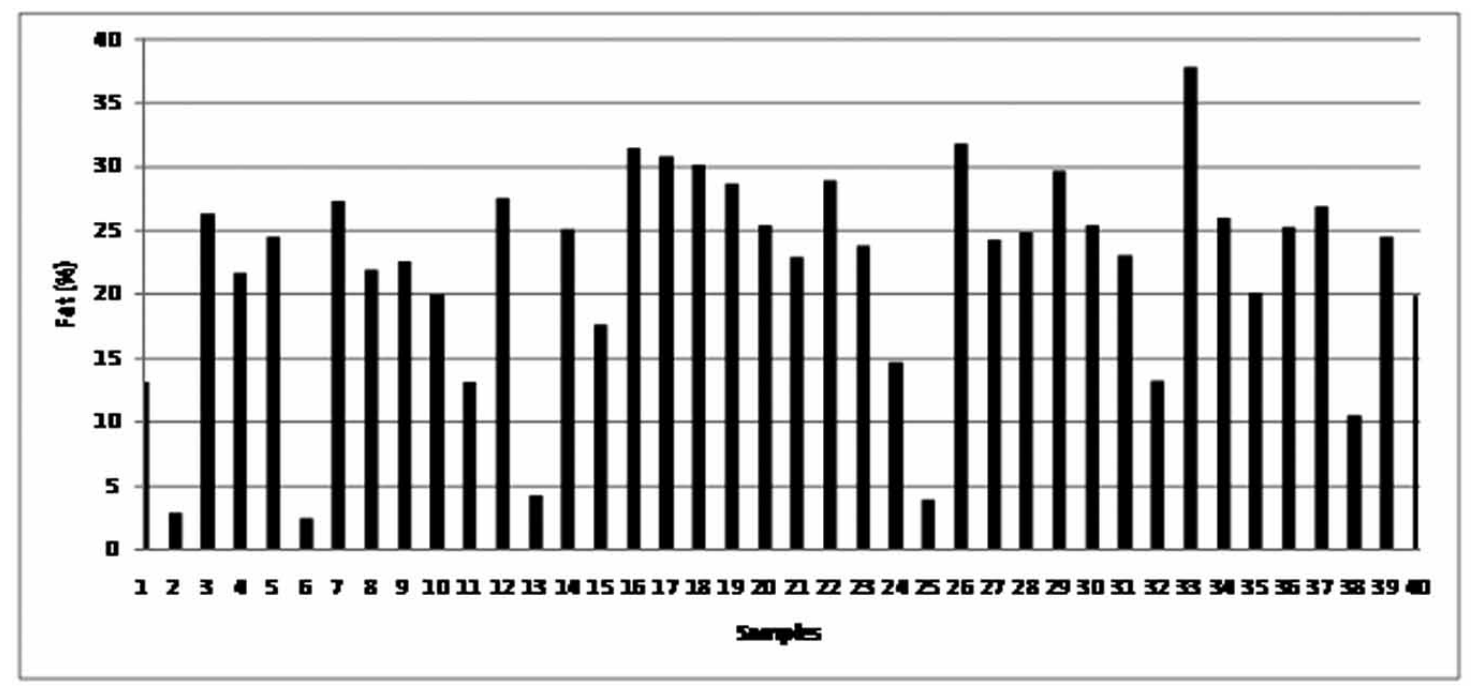

Fig. (1). Total lipid content of 40 samples analysed. 
A

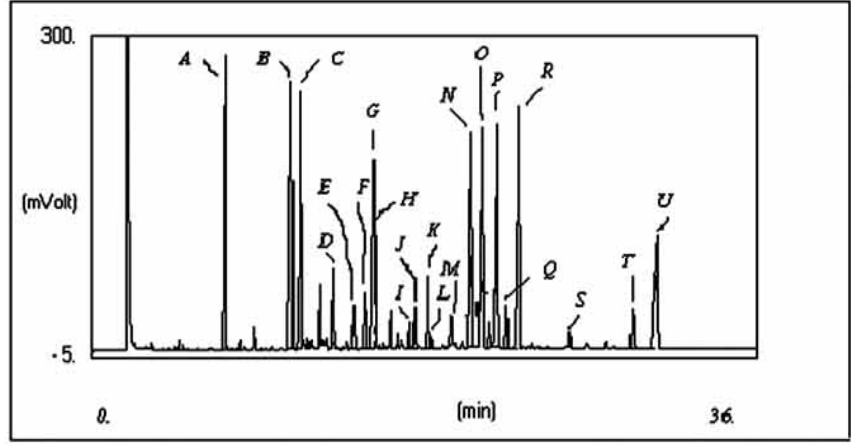

B

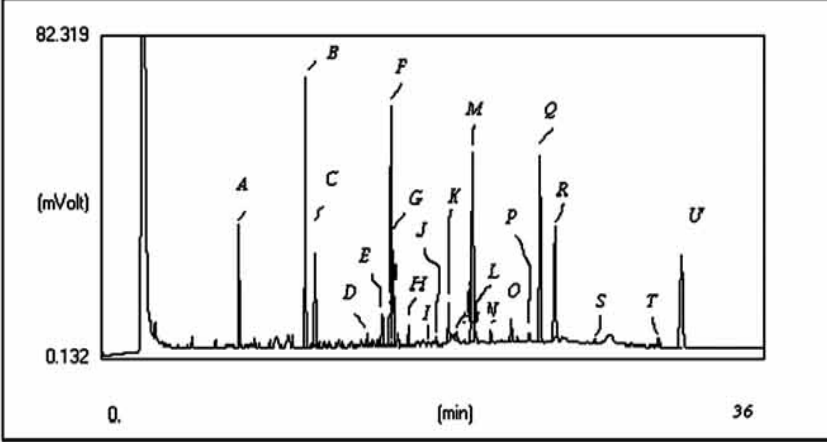

Fig. (2). GC chromatograms of: A) standards of fatty acid methyl esters. B) Snow crab shells. Peaks: (A) C14:0; (B) C16:0; (C) C16:1 07 ; (D)

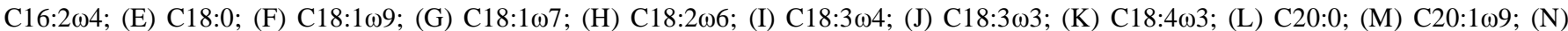

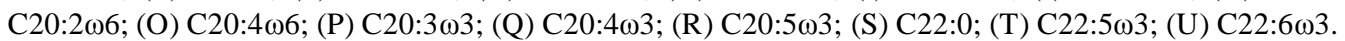

An extraction procedure which involves extractionmethylation in a single step was selected because of its reported advantages, rapidity, simplicity, and low cost [22, 23].
Fig. (2) shows a chromatogram of a standard solution composed by the fatty acid methyl ester mix (PUFA No 3) and cis-11, 14-eicosadienoic acid methyl ester; cis-8, 11, 14eicosatrienoic acid methyl ester and cis-11, 14, 17-

A)

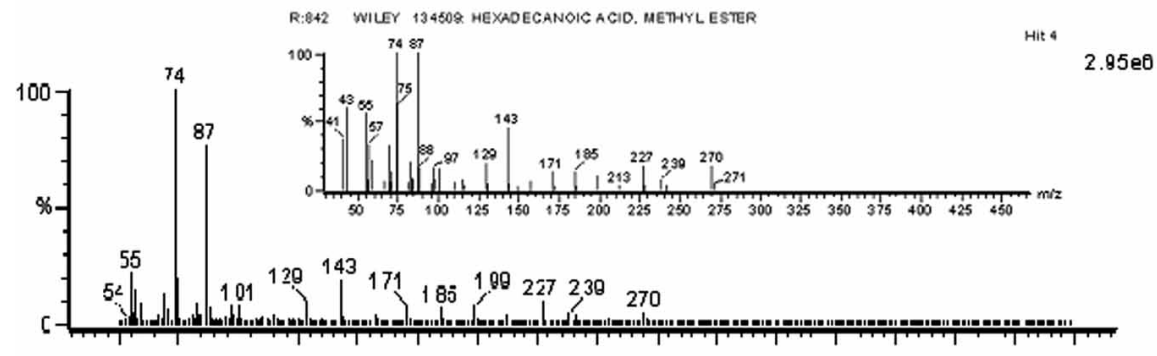

B)

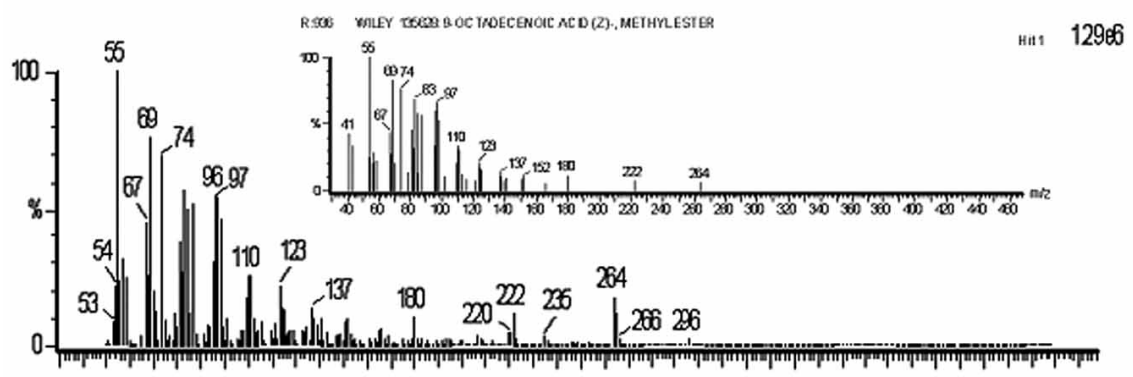

C)

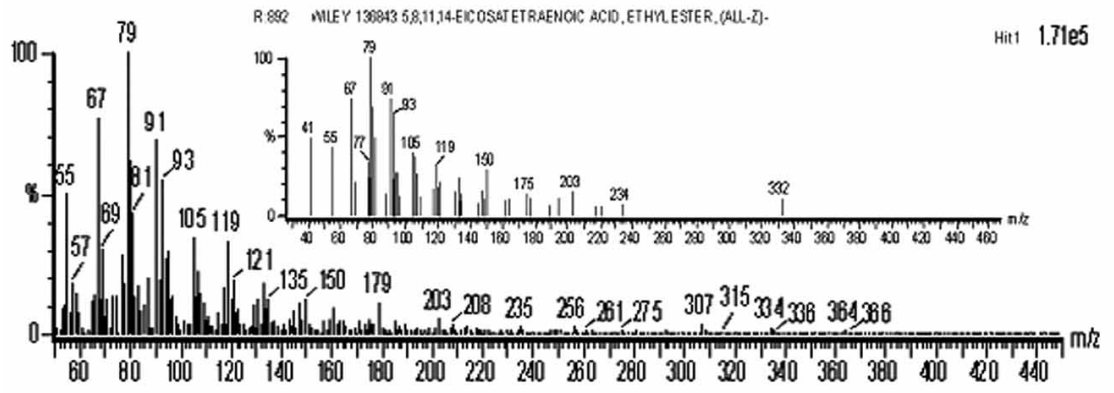

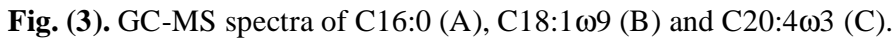


Table 1. Retention Time and Fatty Acid Distribution, Expressed as (g /100g Dry Weight) in Total Lipids, of Chionoecetes opilio Shells

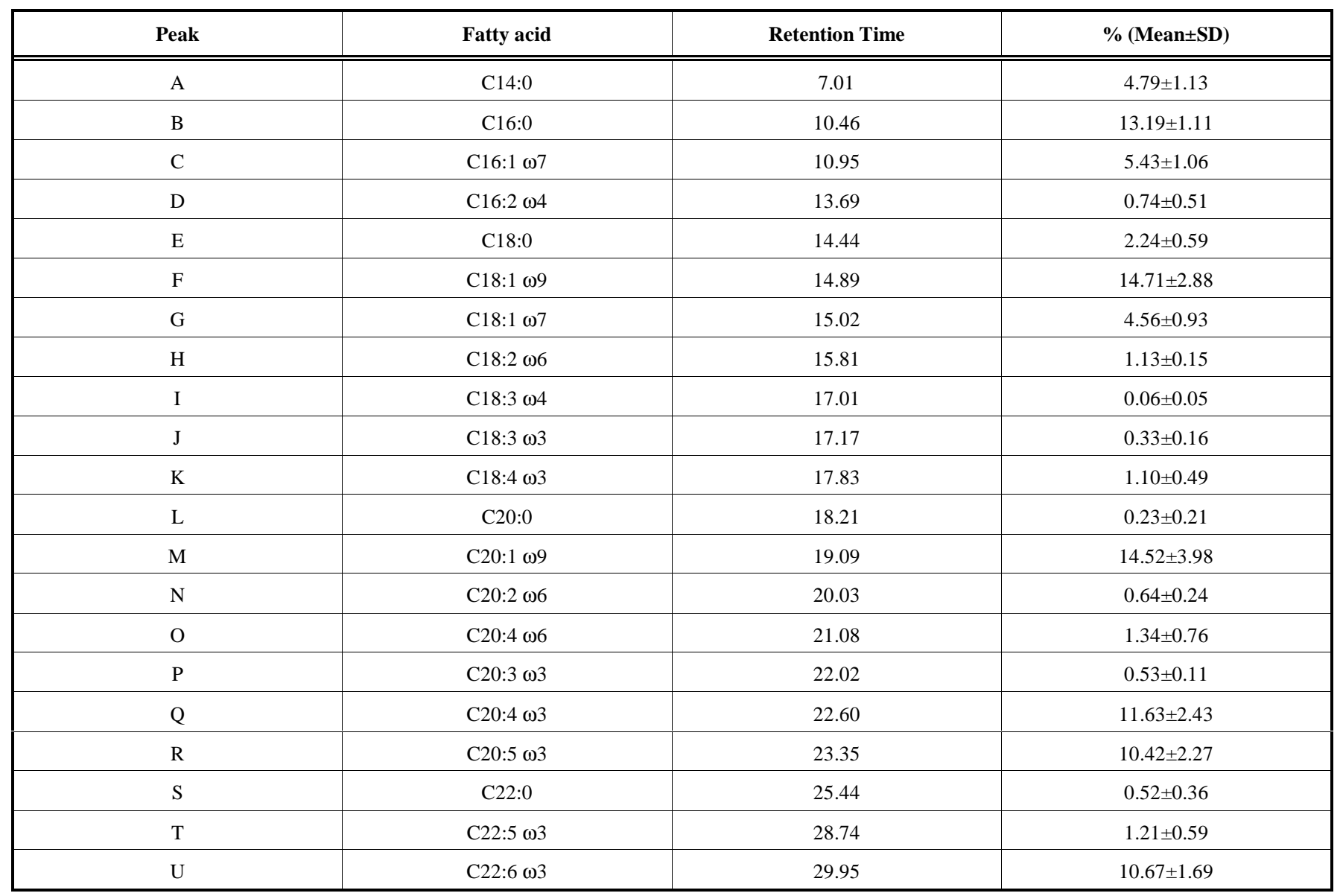

$((\mathrm{n}=40) \pm S . \mathrm{D})$

eicosatrienoic acid methyl ester (A) and a chromatogram of the fatty acids methyl esters obtained from a Chionocetes opilio sample (B).

Identification of fatty acids were based on the comparison of the retention time with an external standard (PUFA No 3) solution and confirmed in the sample extracts by GCMS. The GC-MS spectra corresponding to C16, C18:169 and $\mathrm{C} 20: 4 \omega 3$ are presented in Fig. (3).

The fatty acid distribution in total lipids of the Chionoecetes opilio shells is shown in Table 1. Similar amounts of polyunsaturated fatty acids $(39.80 \%)$ and monounsaturated fatty acids $(39.22 \%)$ were found. The percentage of saturated fatty acids was the lowest representing $21 \%$ of the total fatty acid content (Table $\mathbf{1}$ ).

The main saturated fatty acid is palmitic C16:0 which contributes more than $50 \%$ of the total saturated fatty acids $(13.19 \%)$, these results are in accordance with those reported in shrimp by-products [24, 25] and in crab meat [19-

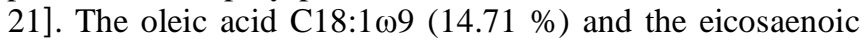

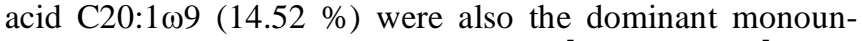
saturated fatty acids in snow crab shells [19-21, 24, 25].

The fatty acid profile of Chionoecetes opilio shells was dominated by polyunsaturated fatty acids, especially $\omega 3$ (35.89\%), with a $11.63 \%$ of eicosatetraenoic acid, $10.67 \%$ of docosahexaenoic acid (DHA), and $10.42 \%$ of eicosapentaenoic acid (EPA). Çelik et al. [20] analysed the fatty acid profile in claw, breast and hepatopancreas of blue crab, and they found that the $\omega 3 / \omega 6$ relationship was higher in the breast (3.18) than in the claw (2.52) or hepatopancreas (1.59).

A $\omega 3 / \omega 6$ fatty acids ratio of 0.45 was reported by Chen $e t$ al. [19] in Chinese mitten crab. In conclusion, the results obtained indicate that snow crab shells might be considered as an innovative source of $\omega 3$ long chain polyunsaturated fatty acids for aquaculture feeding purposes.

\section{ACKNOWLEDGEMENTS}

This work was supported by the Project PGIDIT03BTF00701CT from the Consellería de Innovación, Industria e Comercio da Xunta de Galicia.

\section{REFERENCES}

[1] Gökoolu N, Yerlikaya P. Determinaton of proximate composition and mineral contents of blue crab (Callinectes sapidus) and swim crab (Portunus pelagicus) caught off the Gulf of Antalya. Food Chem 2003; 80: 495-8.

[2] Alvarez AA. Final report: use of the Shell Snow crab as an ingredient of aquaculture diets.2006; Available from: http://www.roxocanval.org/Doc/CangrejoRojo.pdf

[3] Bransden MP, Battaglene SC, Morehead DT, Dunstan GA, Nichols PD. Effect of dietary 22:6n-3 on growth, survival and tissue fatty 
acid profile of striped trumpeter (Latris lineata) larvae fed enriched Artemia. Aquaculture 2005; 243: 331-44.

[4] El-Sayed AM, Mansour CR, Ezzat AA. Effects of dietary lipid source on pawning performance of Nile tilapia (Oreochromis niloticus) broodstock reared at different water salinities. Aquaculture 2005; 248: 187-96.

[5] Li Y, Chen W, Sun Z, Chen J, Wu K. Effects of n-3 HUFA content in broodstock diet on spawning performance and fatty acid composition of eggs and larvae in Plectorhynchus cinctus. Aquaculture 2005; 245: 263-72.

[6] Lane RLL, Trushenki JY, Kohler CC. Modification of fillet composition and evidence of differential fatty acid turnover in sunshine bass Morone chrysops x M. saxatilis following change in dietary lipid source. Lipids 2006; 41:1029-38.

[7] Manning BB, Li MH, Robinson EH, Peterson BC. Enrichment of channel catfish (Ictalurus punctatus) fillets with conjugated linoleic acid and omega-3 fatty acid by dietary manipulation. Aquaculture 2005; 261: 337-42.

[8] Pickova J, Brännäs E, Andersson T. Importance of fatty acids in broodstock diets with emphasis on Arctic char (Salvelinus alpinus) eggs. Aquacult Int 2007; 15: 305-11.

[9] Schlechtriem C, Bron JE, Tocher DR. Inter-individual variation in total fatty acid compositions of flesh of Atlantic salmon smolts-fed diets containing fish oil or vegetable oil. Aquacult Res 2007; 38: 1045-55.

[10] Manirakiza P, Covaci A, Schepens PJ. Comparative Study on total lipid determination using soxhlet, roese-gottlieb, bligh \& dyer, and modified bligh \& dyer extraction methods. J Food Comp Anal 2001; 14: 93-100.

[11] Honeycutt ME, Mcfarl VA, Mc Cant DD. Comparison of three lipid extraction methods for fish. Bull Environ Contam Toxicol 1995; 55: 469-72.

[12] Booij K, Van den Berg C. Comparison of techniques for the extraction of lipids and PCBs from benthic invertebrates. Bull Environ Contam Toxicol 1994; 53: 71-6.

[13] Cheung PCK. Temperature and pressure effects on supercritical carbon dioxide extraction of n-3 fatty acids from red seaweed. Food Chem 1999; 65: 399-403.

[14] Berg H, Mågård M, Johansson G, Mathiasson L. Development of a supercritical fluid extraction method for determination of lipid classes and total fat in meats and its comparison with conventional methods. J Chromatogr A 1997; 785: 345-52.

[15] Erickson MC. Lipid extraction from channel catfish muscle: comparison of solvent systems. J Food Sci 1993; 58: 84-9.

[16] Official Methods of Analysis of the Association of Official Analytical Chemists, $15^{\text {th }}$ ed. USA: AOAC Arlington 1990.

[17] de la Cruz GC, López-Hernández J, Simal LJ. Gas chromatographic determination of the fatty-acid content of heat-treated green beans. J Chromatogr A 2000; 891: 367-70.

[18] Katikou P, Robb DHF. Evaluation and comparison of the CEM rapid extraction method with official standard methods for the determination of lipid content in fillets of farmed Atlantic salmon (Salmo salar). Aquaculture 2001; 194: 99-105.

[19] Chen DW, Zhang M, Shrestha S. Compositional characteristics and nutritional quality of Chinese mitten crab (Eriocheir sinensis). Food Chem 2007; 103:1343-9.

[20] Çelik M, Türeli C, Çelik M, Yanar Y, Erdem Ü, Küçükgülmez A. Fatty acid composition of the blue crab (Callinectes sapidus Rathbun, 1896) in the north eastern Mediterranean. Food Chem 2004; 88: 271-3.

[21] Naczk M, Williams J, Brennan K, Liyanapathirana Ch, Shahidi F. Compositional characteristics of green crab (Carcinus maenas). Food Chem 2004; 88: 429-34.

[22] Sanches-Silva A, Rodríguez-Bernaldo de Quirós A, LópezHernández J, Paseiro-Losada P. Gas chromatographic determination of glycerides in potato crisps fried in different oils. Chromatographia 2003; 58: 517-21.

[23] Sanches-Silva A, López-Hernández J, Paseiro-Losada P, SimalLozano J. Study of the effect of light on fatty acids of potato crisps using a gas chromatographic method. Anal Chim Acta 2004; 524: 191-200.

[24] Shahidi F, Synowiecki J. Isolation and characterization of nutrients and value-added products from snow crab (Chionoecetes opilio) and shrimp (Pandalus borealis) processing discards. J Agric Food Chem 1991; 39: 1527-132.

[25] Heu M, Kim J, Shahidi F. Components and nutritional quality of shrimp processing by-products. Food Chem 2003; 82: 235-42.

Received: February 12, 2009

(c) Martínez et al.; Licensee Bentham Open.

This is an open access article licensed under the terms of the Creative Commons Attribution Non-Commercial License (http://creativecommons.org/licenses/by-nc/3.0/) which permits unrestricted, non-commercial use, distribution and reproduction in any medium, provided the work is properly cited. 